\title{
Tradisi Uang Jaminan dalam Adat Perkawinan di Desa Paling Serumpun Kota Sungai Penuh Kerinci
}

\author{
Debi Lizarman, Susi Fitria Dewi \\ Program Studi Pendidikan Pancasila dan Kewarganegaraan \\ Universitas Negeri Padang \\ E-mail: debilizarman123krc@gmail.com
}

\section{ABSTRAK}

Tradisi uang jaminan berlaku bagi pengantin laki-laki yang berasal dari luar kecamatan, kota/kabupaten dan provinsi di Jambi kepada pihak perempuan. Namun tidak semua pengantin laki-laki memiliki ekonomi yang mapan serta ditambah biaya pesta yang cukup besar. Hal tersebut menjadi penghambat bagi kedua pengantin untuk melangsungkan perkawinan. Tujuan dari penelitian ini adalah mendeskripsikan tradisi uang jaminan dalam adat perkawinan di Desa Paling Serumpun Kota Sungai Penuh Kerinci. Penelitian ini menggunakan penelitian kualitatif dengan metode deskriptif. Teknik Pengumpulan Data penelitian melalui observasi, wawancara dan dokumentasi. Hasil penelitian menunjukkan bahwa pelaksanaan pemberian uang jaminann dalam adat perkawinan di Desa Paling Serumpun Kota Sungai Penuh Kerinci dilakukan secara bajenjing naek batakaoh turang melalui beberapa tahapan. Adapun makna dalam tradisi uang jaminan dalam adat perkawinan di Desa Paling Serumpun Kota Sungai Penuh Kerinci yaitu sebagai bentuk dari laki-laki menyakinkan taganai dalam menikahi anak keponakan perempuannya, penghargaan terhadap perempuan didalam adat setempat, pegangan atau biaya dalam menyelesaikan masalah dan tanggung jawab laki-laki terhadap taganai.

Kata Kunci: tradisi, uang jaminan, perkawinan, kerinci

\section{ABSTRACT}

The tradition of bail applies to the bridegroom from outside the sub-district, city / regency and province in Jambi to the women. But not all grooms have a well-established economy plus a substantial party fee. This is an obstacle for the bride and groom to get married. The purpose of this study is to describe the tradition of bail in customary marriages in the Most Serumpun Village Sungai Sungai Kerinci City. This study uses qualitative research with descriptive methods. Research Data Collection Techniques through Observation, Interview and documentation. The results showed that the implementation of giving guarantee money in the custom of marriage in the Most Serumpun Village of Sungai Penuh Kerinci City was carried out by Bajenjing Naek Batakaoh Turang through several stages. As for the meaning in the tradition of bail in customary marriages in the most cognate village of Sungai Penuh in the Kerinci City, which is a form of men convincing taganai in marrying their niece's daughter, respect for women in local customs, the handle or cost in resolving men's problems and responsibilities against taganai. 
Keywords : tradition, bails, marriage, Kerinci

This work is licensed under the Creative Commons Attribution-ShareAlike 4.0 International License. (2019 by author.

\section{PENDAHULUAN}

Indonesia memiliki banyak pulau dan suku bangsa dengan corak budaya yang beragam. Salah satu corak kebudayaan adalah tradisi yang terus dipertahankan dalam masyarakat. Tradisi merupakan adatistiadat dan kebudayaan yang diwariskan secara turun-temurun serta dipelihara oleh masyarakat (Soekanto, 1983:381). Masing-masing suku di Indonesia memiliki kebudayaan khas dalam tradisi perkawinan. Masyarakat suku Kerinci menganut sistem matrilineal atau keturunan ibu. Terdapat tradisi unik pada perkawinan masyarakat suku Kerinci di daerah Desa Paling Serumpun Kota Sungai Penuh Kerinci yang bernama tradisi uang jaminan. Uang jaminan adalah uang yang diberikan oleh pihak laki-laki yang berasal dari luar daerah Kecamatan, Kota/Kabupaten Dan Provinsi kepada pihak perempuan.

Tradisi uang jaminan perkawinan di desa ini memunculkan permasalahan bagi pengantin laki-laki yang berasal dari luar daerah tersebut. Pengantin laki-laki merasa diasingkan dari budayanya. Tidak semua masyarakat dan pengantin laki-laki yang memahami makna uang jaminan yang diminta oleh pihak pengantin perempuan. Selain itu tidak semua pengantin laki-laki memiliki ekonomi yang mapan serta ditambah biaya pesta yang cukup besar. Oleh sebab itu pengantin laki-laki tidak bisa memberi uang jaminan sesuai dengan ketetapan yang berlaku. Hal tersebut menjadi penghambat bagi kedua pengantin untuk melangsungkan perkawinan.
Penelitian ini berangkat dari penelitian sebelumnya yaitu Manik (2011) tentang makna dan fungsi tradisi sinamot dalam adat perkawinan suku bangsa batak toba di perantauan Surabaya. Tradisi sinamot merupakan sarana pengikat antara kelompok kekerabatan dan memperkuat integritas sosial. Penelitian yang dilakukan oleh Makki (2017) menganalisis tentang hukum islam terhadap uang jujur (jojokh) dalam perkawinan adat Lampung Selatan. Uang jujur sama dengan mahar tapi dalam menentukan jumlah sesuai dengan kesepakatan kedua belah pihak atau tidak memberatkan pihak laki-laki. Kalimatul Ulfah dkk (2012) meneliti tentang pelaksanaan tradisi ngemblok dalam perkawinan di Kecamatan Sale Kabupaten Rembang. Kedatangan pihak perempuan ke pihak laki-laki dengan membawa sejumalah uang dan emas dalam bentuk seserahan.

Widyawati (2018) dalam tulisannya meneliti tentang makna tradisi uang panai dalam adat perkawinan Suku Bugis di Sungai Gunting Kecamatan Kateman Kabupaten Indragiri Hilir Provinsi Riau. Sejumlah uang yang dibayarkan pihak laki-laki kepada pihak perempuan sebagai bentuk penghargaan terhadap perempuan Bugis. Hafizah (2017) meneliti tentang tradisi uang japuik dan uang ilang dalam sistem perkawinan di Negari Tandikek Kecamatan Patamuan Kabupaten Padang Pariaman. Proses pembayaran uang japuik dan uang ilang yang dilakukan oleh mamak 
kedua belah pihak dengan makna sebagai bentuk kebanggaan bagi lakilaki.

Tidak semua masyarakat memahami kegunaan uang jaminan. Tidak semua pengantin laki-laki yang memiliki ekonomi yang mapan. Tradisi uang jaminan dilaksanakan bagi pengantin laki-laki yang berasal dari luar daerah supaya tidak terjadi salah pemahaman dalam masyarakat terhadap uang jaminan. Berdasarkan uraian di atas telah dilakukan penelitian tentang tradisi uang jaminan dalam adat perkawinan di Desa Paling Serumpun Kota Sungai Penuh Kerinci.

Mamfaat dari penelitian untuk mendeskripsikan pelaksanaan pemberian dan makna dalam tradisi uang jaminan dalam adat perkawinan di Desa Paling Serumpun Kota Sungai Penuh Kerinci. Penelitian ini juga bertujuan untuk memberikan pemahaman tentang uang jaminan dalam konteks ilmiah kepada masyarakat. Selanjutnya penelitian ini dapat membantu pembaca memahami tradisi uang jaminan dalam adat perkawinan di Desa Paling Sermpun Kota Sungai Penuh Kerinci setidaktidaknya sebagai salah satu tradisi masyarakat. Dengan harapan masyarakat bisa menjaga tradisitradisi yang ada disekitarnya.Dapat mengurangi hambatan-hambatan yang terdapat dalam proses penentuan juamlah uang jaminan yang dibayarkan.

\section{METODE PENELITIAN}

Jenis penelitian yang digunakan dalam penelitian ini adalah kualitatif dengan metode deskriptif. Jenis fokus penelitian ini adalah penelitian deskriptif kualitatif karena penulis bertujuan mendeskripsikan atau menggambarkan tradisi uang jaminan dalam adat perkawinan. Dengan informan para depati ninik mamak, tokoh masyarakat dan masyarakat yang terlibat dalamya. Lokasi penelitian di Desa Paling Serumpun Kota Sungai Penuh Kerinci. Pengumpulan data melalui observasi, wawancara dan dokumentasi. Teknik analisis data adalah reduksi data, display data dan penarikan kesimpulan.

\section{HASIL DAN PEMBAHASAN}

Pelaksanaan pemberian uang jaminan dalam adat perkawinan di Desa Paling Serumpun Kota Sungai Penuh Kerinci

Setiap daerah memiliki adat atau tradisi yang menjadi pembeda dari daerah lain. Hal ini termuat dalam petitih adat yaitu 'lain padang lain belalang, lain lubuk lain ikannya'. Koentjaraningrat (dalam Kalimatul Ulfah, dkk, 2012) mengatakan bahwa pemberian sejumlah harta dari pihak laki-laki kepada pihak perempuan untuk melangsungkan perkawinan dan disaksikan kerabatnya sebagi bentuk pengikatan hubungan mereka. Pemberian sejumlah harta dari lakilaki kepada perempuan yang menjadi penguat ikatan hubungan yang lebih baik lagi.

Persyaratan pengantin dalam melaksanakan perkawinan berdasarkan agama dan adat yang berlaku didaerah setempat. Pelaksanaan pemberian tradisi uang 
jaminan dalam adat perkawinan di Desa Paling Serumpun Kota Sungai Penuh Kerinci dilakukan secara bajenjing naek batakaoh turang dengan tahapan:

\section{a) Batuwok atau melamar}

Ketika seorang anak keponakan perempuan menikah dengan laki-laki dari luar atau dalam daerah maka disebut orang masuk dan orang keluar. Sebelum menentukan hari, tanggal, tempat dan waktu kedua belah pihak melakukan pertemuan yang disebut batuwok atau melamar. Kalimatul Ulfah, dkk(2012) menyebutkan pembicaraan yang terjadi antar kedua belah pihak yaitu menanyakan apakah benar laki-laki dan perempuan belum memiliki pasangan. Pembicaraan tersebut dilakukan secara langsung antara orang tua atau melalui kurir. Dalam pertemuan ini menanyakan keseriusan antara calon pengantin lakilaki dan perempuan. Pertemuan dilakukan oleh masing-masing utusan kedua belah pihak pada malam hari setelah sholat Isya dalam waktu dua malam. Malam pertama pihak laki-laki kerumah pihak perempuan pada malam kedua sebaliknya. Pertemuan yang menyampaikan tentang adat atau tradisi kedua belah pihak.

b) Ngantok paltauk atau memberikan tanda jadi

Malam ketiga pihak laki-laki kerumah pihak perempuan sekaligus memberikan tanda jadi atau nagantok paltauk. Kalimatul Ulfah, dkk (2012) memberikan sejumlah harta sebagai tanda dari ikatan kedua belah pihak yang disesuaikan aturan yang berlaku di masyarakat setempat. Pada malam tersebut disampaikan kesepakatan tentang jumlah uang jaminan yang diberikan oleh pihak laki-laki. Rahayu dan Yudi (2015) menyatakan ini sebagai proses peresmian lamaran dan menyampaikan kesepakatan. Penyampaian seluruh keputusan yang telah diperundingkan dalam masa lamaran. Depati ninik mamak dua belah pihak menjadi saksi atas kesepakatan yang telah dibuat melalui masing-masing utusan keluarga.

Ninik mamak kalbu menyiapkan jawaban dari pertanyaan para depati ninik mamak pada malam berikutnya. Ini menjadi pengikat laki-laki dan perempuan dalam pergaulan mudamudi agar mampu terhindar dari hal buruk sebelum acara perkawinan dilaksanakan. Pihak keluarga perempuan memberitahu kepada masyarakat sekitar untuk hadir dalam acara tersebut. Dari pihak perempuan menyiapkan hidangan menyambut kedatangan pihak laki-laki yang membawa rombongan dalam jumlah yang besar.

c) Ngibeuk sukui dumeh atau mengumpulkan kerabat dalam satu keluarga dan depati ninik mamak dalam satu kalbu

Taganai menyampaikan hasil pertemuan malam yang sebelumnya kepada kerabat dan depati ninik mamak dalam satu kalbu. Taganai 
kemudian meminta izin dan arahan dalam menyiapkan keperluan selama pesta perkawinan yang berlangsung dengan waktu yang panjang. Hafizah (2017) menyampaikan bahwa waktu pernikahan, keluarga benar-benar sibuk dalam menyiapkan kebutuhan pesta perkawinan yang dihadiri oleh mamak. Pihak keluarga pengantin parempuan menjawab pertanyaan yang disampaikan oleh depati ninik mamak mulai dari kesiapan perlengkapan untuk acara, penjelasan masa lamaran sampai hari puncak pesta perkawinan, penjelasan mengenai diri dari pengantin laki-laki dan bagaimana tanggapan dari saudara pihak ayah serta ibu dari pengantin perempuan.

Jika semua pertanyaan telah terjawab, para ninik mamak memberikan izin untuk tahapan berikutnya yaitu Ngibeuk tuwui atau mengumpulkan masyarakat luas dan depati ninik mamak baik dalam maupun diluar kalbu. Pada malam ini, masyarakat mengenal tradisi ini dengan istilah menulis atau nulaih. Nulaih adalah masyarakat menuliskan sumbangannya pada buku yang telah sebarkan oleh pihak pengantin perempuan baik berupa uang atau sembako yang diperlukan dalam pesta nantinya. Ini sebagai bentuk dari dukungan masyarakat dalam menyukseskan pesta perkawinan tersebut.

d) Ngibeuk tuwui atau mengumpulkan masyarakat luas dan depati ninik mamak dari dalam maupun diluar kalbu

Zakaria (1983:129) mengatakan bahwa izin atau pemberitahuan kepada masyarakat luar merupakan sebuah keharusan dalam negeri ketika mengadakan pesta yang besar. Penyampaian parno adat oleh anak laki-laki dan anak perempuan dengan memberikan sirih pinang sebagai bentuk minta izin dan arahan para depati ninik mamak. Sirih pinang diletakkan di depan ninik mamak dan depati yang akan menjawab parno adat dan memberikan izin untuk melaksanakan pesta perkawinan anak keponakannya di dalam negeri. Disini ninik mamak yang menyampaikan tantang acara yang akan dilakukan mulai dari masa lamaran sampai hari puncak pesta perkawinan kepada pemucuk adat atau depati.

Uang adat, uang jaminan dan mahar dijelaskan sesuai dengan kesepakatan pada malam yang sebelumnya. Dengan harapan tidak terjadi masalah dengan uang adat, uang jaminan dan mahar yang diberikan oleh pengantin laki-laki ketika akad nikah dilaksanakan. Jumlah uang jaminan yang diberikan oleh pengantin laki-laki ketika akad nikah disampaikan pada waktu tersebut. Malam tersebut sebagai waktu untuk membayarkan apa yang sudah dituliskan pada buku sumbangan ketika ngibeuk sukui dumeh atau mengumpulkan kerabat dalam satu keluarga dan depati ninik 
mamak dalam satu kalbu. Setelah dirasakan jelas semua, para depati ninik mamak memberikan izin untuk memberitahu kepada masyarakat umum. Keesokan harinya masyarakat umum datang ker umah tempat pesta perkawinan dengan membawa beras, kelapa, gula pasir dan sebagainya.

e) Acara akad nikah

Kusmayadi menyampaikan bahwa kedua pengantin terlebih dahulu memenuhi persyaratan administrasi yang sesuai ketentuan adat yang berlaku di daerah ini. Pada waktu acara akad nikah, para depati ninik mamak duduk berdasarkan gelar yang disandangnya. Anak laki-laki dan anak perempuan menyampaikan parno adat dengan memberikan sirih pinang kepada para depati ninik mamak dengan maksud melaksanakan akad nikah dan penyelesaian secara adat.

Parno adat disampaikan sesuai sko tigo takah yaitu sko anak jantan, sko ninik mamak dan sko depati. Anak laki-laki menyampaikan kepada ninik mamak serta menyerahkan mahar, uang adat dan uang jaminan sebelum melaksanakan akad nikah. Ninik mamak menyampaikan kepada depati agar mendapatkan persetujuan untuk acara ini sebagai pemucuk adat. Di dalam adat, depati akan memutuskan perkara yang bersifat makao aboih, ngehaok putauh dan muneh matai. Semua perkara yang ada di masyarakat pasti selesai kalau sampai tingkat depati penyelesaiannya. Jika sudah mendapatkan izin dari depati, maka ninik mamak mulai memberikan izin kepada penghulu untuk melaksanakan akad nikah kedua pengantin.

Makna dalam tradisi uang jaminan dalam adat perkawinan di Desa Paling Serumpun Kota Sungai Penuh Kerinci

Sejarah uang jaminan telah adat sejak dahulu adat perkawinan di masyarakat Desa Paling Serumpun Kota Sungai Penuh Kerinci sampai sekarang. Adat lamo pusako usang, idak lekan dek paneh dan idak lapuk diujan sebagai ungkapan untuk uang jaminan. Adapun makna dalam tradisi uang jaminan dalam adat perkawinan di desa tersebut sebagai berikut:

a) Sebagai bentuk dari laki-laki menyakinkan taganai dalam menikahi anak keponakan perempuannya. Kusmayadi (2018) menyampaikan suami bertanggung jawab terhadap kebutuhan dan pelindung dalm rumah tangga. Memberikan kepercayaan kepada orang luar atau asing sangat sulit. Apalagi ingin menikahi anak keponakan perempuan kita sedangkan si laki-laki yang belum kita kenal tingkah lakunya dan dari keluarga mana dia. Setelah si laki-laki memberikan uang jaminan bukan berarti seenaknya berbuat kepada si perempuan atau istrinya. Laki-laki harus mampu memenuhi kebutuhan rumah tangga, menjadi pelindung untuk istri dan anaknya kelak. 
b) Penghargaan terhadap perempuan didalam adat setempat. Menurut Tius(2018), laki-laki memberikan sesuatu kepada perempuan yang sesuai dengan adat, sehingga bisa memperkuat integritas sosial. Walaupun pemimpin dalam adat adalah laki-laki, bukan berarti perempuan tidak diperhatikan oleh adat. Masyarakat memperlihatkan bahwa perempuan didaerah sini berbeda dengan yang lain ketika ingin meminangnya. Maka laki-laki tidak berbuat hal buruk kepada istrinya sebagai bentuk menghargai adat istrinya.

c) Pegangan atau biaya dalam menyelesaikan masalah. Aturan adat berfungsi sebagai petunjuk bagi kedua pengantin agar tidak menimbulkan masalah Kusmayadi (2018). Kadangkadang baru berumah tangga belum bisa memahami satu sama lain sehingga dapat memicu masalah. Ketika laki-laki sampai melarikan diri atau kembali kerumah orang tuanya, teganai harus melihat atau mencari kemana laki-laki ini melarikan diri dan sebagai biayanya menggunakan uang jaminan tersebut. Sehingga taganai dan keluarganya tidak terganggu dalam menyelesaikan masalah anak keponakan perempuannya. Secara tidak langsung keluarga dan kerabat tidak ada pemasukan.

d) Tanggung jawab laki-laki terhadap taganai. Perkawinan merupakan hal yang sakral dan tidak boleh dimainkan. Rahman (2016) menyatakan sebagai harga diri yang harus diperjuangkan melalui usaha keras dijuntukan pada perempuan yang dilamar bahwa laki-laki mampu memenuhi yang diminta perempuan. Dalam adat kerinci perkawinan sebagai tempat membelanjakan harta dan memakan waktu yang lama sebagai bentuk pengerbanan orang tua kepada anak. Ketika akad nikah separoh tanggung jawab seorang teganai sudah dilimpahkan kepada suami atau laki-laki. Apapun yang terjadi dalam rumah tangga mereka dan merugikan di anatara mereka. Suami atau laki-laki harus mampu menyampaikan dan tangggung jawab dengan hal yang terjadi. Sehingga taganai tidak buru-buru dalam mengambil langkah dalam penyelesaian.

\section{SIMPULAN}

Pelaksanaan pemberian uang jaminan dalam adat perkawinan di Desa Paling Serumpun Kota Sungai Penuh Kerinci dilakukan secara bajenjing naek batakaoh turang melalui beberapa tahapan yaitu Batuwok atau melamar, Ngantok paltauk atau memberikan tanda jadi, Ngibeuk sukui dumeh atau mengumpulkan kerabat dalam satu keluarga dan depati ninik mamak dalam satu kalbu, dan Ngibeuk tuwui atau mengumpulkan masyarakat luas dan depati ninik mamak baik dalam maupun diluar kalbu dan terakhir acara akad nikah. Adapun makna dalam tradisi uang jaminan dalam adat perkawinan di desa tersebut yaitu sebagai bentuk dari laki-laki meyakinkan taganai dalam menikahi 
anak keponakan perempuannya, penghargaan terhadap perempuan didalam adat setempat, pegangan atau biaya dalam menyelesaikan masalah, dan tanggung jawab laki-laki terhadap taganai.

\section{DAFTAR PUSTAKA}

Rahman, Abd. 2016. Analisis Penerimaan Khalayak Terhadap Tradisi Uang Panai' Dalam Film Uang Panai' 2016. Surabaya. Jurnal Universitas Airlangga.

Hafizah. 2017. Tradisi Uang Japuik Dan Uang Ilang Dalam Sistem Perkawinan Di Nagari Tandikek Kecamatan Patamuan Kabupaten Padang Pariaman. Jurnal Kepemimpinan Dan Pengurusan Sekolah Vol. 2 Maret Tahun 2017 (page 17-26) e- ISSN: 2502- 6445 P- IISN: 2502- 6437.

Manik, Helga Septiani. 2011. Makna Dan Fungsi Tradisi Sinamot Dalam Adat Perkawinan Suku Bangsa Batak Toba Di Perantauan Surabaya.Biokultur Vol. 1 No. 1 Januari-Juni 2112 Hal. 19.

Makki, Hud Leo Perkasa. 2017. Analisis Hukum Islam Terhadap Uang Jujur (Jojokh) Dalam Perkawinan Adat Lampung Pesisir. Jurnal Hukum Dan Ekonomi Syariah Vol. 05 Meret 2017.

Ulfah, Kalimatul dkk. 2012. Pelaksanaan Tradisi Ngemblok Dalam Perkawinan(Studi Kasus Di Kecamatan Sale Kabupaten Rembang). Unnes Civic Education Journal 1 (1) (2012). ISSN 2252-7133.

Rahayu, Sri dan Yudi. 2015. Uang Nai': Antara Cinta Dan Gengsi.
Jurnal Akuntansi Multiparadigma JAMAL Vol 6 No 2 Hal 175-340 Malang, Agustus 2015 ISSN 2086-7603 eISSN 2089-5379.

Tius, Tommy. 2018. Makna Dan Fungsi

Tradisi Sinamot Dalam

Pernikahan Batak Toba Di

Kecamatam Mandau. JOM

FISIP Vol. 5: Edisi II Juli-

Desember 2018.

Widyawati. 2018. Makna Tradisi Uang

Panai Dalam Adat Perkawinan

Suku Bugis Di Sungai Guntung

Kecamatan Kateman

Kabupaten Indragiri Hilir

Provinsi Riau. JOM FISIP Vol. 5:

Edisi II Juli-Desember 2018.

Kusmayadi, Yudi. 2018. Tradisi Sawer

Penganten Sunda Di Desa

Parigi Kecamatan Parigi Kabupaten Pangandaran. Jurnal Agastya Vol 8 No 2 Juli 2018

Zakaria, Iskandar. 1983. Tambo Sakti

Alam Kerinci. 1 Jilid 